\title{
Waste electrical and electronic equipments as urban mines in Burkina Faso: Characterization and release of metal particles
}

\author{
Francis O. Konaté ${ }^{a, e, *}$, Philippe Ancia ${ }^{\mathrm{b}}$, Fousseni Soma ${ }^{\mathrm{c}, \mathrm{d}}$, Moussa Bougouma ${ }^{\mathrm{c}}$, \\ Claudine Buess-Herman ${ }^{\mathrm{d}}$, Arsène H. Yonli ${ }^{\mathrm{e}}$, Véronique Vitry ${ }^{\mathrm{a}}$ \\ a Service de Métallurgie, Faculté Polytechnique, Université de Mons, 56 Rue de l'Epargne, 7000 Mons, Belgium \\ ${ }^{\mathrm{b}}$ Service du Génie Minier, Faculté Polytechnique, Université de Mons, 56 Rue de l'Epargne, 7000 Mons, Belgium \\ ${ }^{\mathrm{c}}$ Laboratoire de Chimie des Matériaux et de l'Environnement (LCME), Unité de Formation et de Recherche en Sciences et Technologies (UFR-ST), Université Norbert \\ ZONGO de Koudougou (U-NZK), BP 376 Koudougou, Burkina Faso \\ ${ }^{\mathrm{d}}$ Chemistry of Surfaces, Interfaces and nanomaterials, Faculté des Sciences, Université libre de Bruxelles (ULB), Boulevard du Triomphe, 2, CP 255, B-1050 Bruxels, \\ Belgium \\ ${ }^{\mathrm{e}}$ Laboratoire de Génie des Procédés - Ingénieurie Biologie Santé (LaGeP-IBS), Université Joseph KI-ZERBO, 03 B.P. 7021 Ouagadougou 03, Burkina Faso
}

\section{A R T I C L E I N F O}

\section{Keywords:}

WEEE

PCBs

Metals release

Chemical elements characterization

Metals distribution

\begin{abstract}
A B S T R A C T
Like other developing countries, Burkina Faso is one of the preferential destinations for second-hand electrical and electronic equipments (EEE). At the end of their life, these EEEs are classified as waste electrical and electronic equipment (WEEE) including Printed Circuit Boards (PCB). A particle size reduction is realized for the release of metals by shredding and grinding to obtain particles smaller $1.5 \mathrm{~mm}$. A granulometric sorting was realized and nine granulometric portions were obtained. Particles were characterized by optical microscopy and Scanning Electron Microscopy coupled with Energy Dispersive X-ray Spectroscopy (EDS). The experiments confirmed that the fractions contained polymers, glass fibers and metals under the form of single metals or alloys. The release of metal was efficient for particles with a size smaller than $0.71 \mathrm{~mm}$. Three digestion procedures were experimented on four components to assess the impact on metals leaching. Microwave-assisted digestion method was the best procedure, compared to the analysis methods ISO 11466: 1995, and method 3050B, adapted. The characterization by Inductively coupled plasma atomic emission spectroscopy (ICP-AES) of these PCBs exhibited important amounts of precious metals ( $\mathrm{Ag}, \mathrm{Au}, \mathrm{Pd}$ ) and other metals in greater quantities $(\mathrm{Cu}, \mathrm{Pb}, \mathrm{Ni}, \mathrm{Co}, \mathrm{etc}$.), leading to their qualification as "Urban Mines" calling for their recovery. The characterization of metals in each granulometric portion is realized. Precious and others metals were distributed in all granulometric size portions. So granulometric size reduction was not efficient for metal separation and recovery from PCBs and alternative methods should be investigated for selective precious metal recovery.
\end{abstract}

\section{Introduction}

The global amount of waste electrical and electronic equipments (WEEE) is increasing dramatically, causing important health and environmental concerns (Ghosh et al., 2015). Electronic waste (e-waste) consists of several types of materials: plastics (polyethylene, polypropylene, polyesters, and polycarbonates), recoverable metals (Ag, Al, $\mathrm{Au}, \mathrm{Br}, \mathrm{Ca}, \mathrm{Co}, \mathrm{Cu}, \mathrm{Fe}, \mathrm{Mn}, \mathrm{Nb}, \mathrm{Ni}, \mathrm{Pd}, \mathrm{Pt}, \mathrm{Si}, \mathrm{Sn}, \mathrm{Ti}, \mathrm{Ta}, \mathrm{Zn}$ ), toxic metals ( $\mathrm{Cr}, \mathrm{Pb}, \mathrm{Hg}, \mathrm{Cd}$, etc.) and organic compounds (tetrabromo-bisphenol A, polychlorinated biphenyls, hexabromocyclododecane, polybrominated diphenyl ether used as flame retardants in Printed Circuit Boards (PCBs), etc. (Cesaro et al., 2018; Tian et al., 2018; Guo et al., 2011; Hadi et al.,
2015; Souza et al., 2017). Because of toxic substances in e-waste with significant risk levels for human health and the environment, responsible management of end-of-life WEEE has to be promoted (Achillas et al., 2013). Current e-waste management strategies recommend recycling for better control of toxic metals such as $\mathrm{Pb}, \mathrm{Hg}, \mathrm{Cd}$, Be, etc., when WEEE are landfilled or incinerated. An additional good e-waste management strategy is the recovery of precious and special metals ( $\mathrm{Au}, \mathrm{Ag}$, $\mathrm{Pd}, \mathrm{Cu}, \mathrm{Pt}$, etc.) for the generation of economic income. In addition to locally generated WEEE, African and Asian countries are the main destinations for many second-hand EEE from the rest of the world (Bimir, 2020; Li et al., 2013; Ongondo et al., 2011). The widespread recycling techniques for electronic waste in Africa are basic and the lack of

\footnotetext{
* Corresponding author.

E-mail address: konatefrancis@yahoo.fr (F.O. Konaté).
} 
technical facilities and skills make a challenge of the handling and recycling of hazardous materials (Rajarao et al., 2014). The typical ewaste management strategies consist of the collection and manual dismantling of WEEE, and uncontrolled incineration for the recovery of metals, emitting hazardous components in the atmosphere (Rajarao et al., 2014). Besides countries with poor WEEE management practices, some African countries as Ghana, Nigeria, Kenya, Egypt, etc., (Bimir, 2020; Maphosa et al., 2020) have well-organized sectors for WEEEs recycling, generating important amounts of recovered materials mainly $\mathrm{Fe}$, steel, $\mathrm{Al}$, and $\mathrm{Cu}$ (Rachid, 2018). In Burkina Faso, both formal and informal sectors are in charge of the collection, dismantling, and sorting of WEEE. Available metals from dismantling ( $\mathrm{Fe}, \mathrm{Al}$, and $\mathrm{Cu}$ ) are recovered manually and sold to local artisans. Plastics, screens, and printed circuit boards are most of the time exported to developed countries for recycling. Printed circuit boards (PCBs) contain large fractions of metals deposited on substrates (Alzate et al., 2016; Jadhav and Hocheng, 2015). PCBs represent up to 4 or $7 \%$ of the total mass of WEEE (Li et al., 2018) and are essentially composed by three types of materials: organic materials, ceramics, and metals (Hubau et al., 2019; Khaliq et al., 2014; Shittu et al., 2021). Precious metals constitute the largest share in terms of the added value of recycling WEEE (Zhang et al., 2017), hence their name "urban mines" (Arora et al., 2017). This category of WEEE in sub-Saharan Africa is partly intended for export to developed countries for more efficient and effective treatment (Kaya, 2016). Therefore, it is suitable to design and implement in developing countries appropriated facilities for precious metals recovering to optimize income generation from urban mines.

Four PCBs types were concerned by the present study: cell phone printed circuit boards, computer printed circuit boards, Random Access Memory (RAM), and Processors. These four types of PCBs are representative of the collected and exported PCBs from Burkina Faso (Rachid, 2018).

Pretreatment is the first step in the recovery process. It consists of metal release from other materials by particle size reduction. Mechanical processes are recommended compared to pyrolysis which is less protective for the environment because of harmful gas emissions (Buekens and Yang, 2014). The key role of pretreatment techniques on the release of metals from plastics, cardboard, and other materials is well established. For characterization of chemicals elements in PCBs, grinding methods is also appropriate for samples preparation, for a best leaching of the metals. And it is more interesting to realize a fine grinding. Ogunniyi et al. (2009) and Kitane et al., (2015) reported respectively studies about fine grinding and shredding followed by pyrolysis as techniques promoting metal particles liberation.

For an efficient metal release from supporting materials, a two-step particle size reduction process was reported (Lee et al., 2017; Wang et al., 2018). The first step consisted of shredding and the second one of finer grinding. Sarvar et al. (2015) reported a complete release of metals from plastic, ceramic and cardboard respectively for the following particle size portions (in millimeters): [1.68 - 2.38], [0.21-0.42] and < 0.21 .

Dissolution of resulting particle portions in wet solutions was also carried out by two digestion methods: open environment digestion by heating on a hotplate (Petter et al., 2014) and microwave-assisted digestion in closed environment. According to literature, many leaching solutions are available for metal digestion: $\mathrm{HNO}_{3}-\mathrm{HCl}, \mathrm{HF}, \mathrm{H}_{2} \mathrm{SO}_{4}$ $\mathrm{H}_{2} \mathrm{O}_{2}, \mathrm{HCl}, \mathrm{HNO}_{3}$, fusion with $\mathrm{Na}_{2} \mathrm{O}_{2}$ or $\mathrm{LiBO}_{2}$ followed by dissolution in dilute $\mathrm{HCl}$ solution. Ogunniyi et al. (2009) compared some digestion procedures and showed that dissolution in aqua regia was better than microwave digestion with a mixture of $\mathrm{HNO}_{3}$ and $\mathrm{HF}$, and then fusion with $\mathrm{Na}_{2} \mathrm{O}_{2}$ followed by dissolution in $\mathrm{HCl}$ solution. Some other authors (Mičková et al., 2018; Subhabrata and Yen-Peng, 2017; Tunali et al., 2020) showed that $\mathrm{H}_{2} \mathrm{O}_{2}$ added to acid solutions $\left(\mathrm{HCl}\right.$ and $\mathrm{HNO}_{3}$ ) was more effective and less harmful than aqua regia, but this digestion procedure has been only the subject of few recent publications.

The present study aims to, assess the method for particle size reduction to ensure efficient metal release from PCBs, determine the most suitable digestion procedure to ensure accurate quantitation of metals in PCBs, and to establish the relation between particle size and metal content.

\section{Materials and methods}

The four components of printed circuit boards (PCBs) that are the motherboard PCBs, mobile phones PCBs, processors, random access memory were provided by a local WEEE dismantling unit in Ouagadougou (Burkina Faso, West Africa), "Association Burkinabé pour la Promotion des Emplois Verts (ABPEV)". Analytical grade $\mathrm{HNO}_{3}$ (65\%) and $\mathrm{HCl}(37 \%)$ reagents for metal digestion, and standard solutions for instrument calibration were provided by VWR. Analytical grade $\mathrm{H}_{2} \mathrm{O}_{2}$ (30\%) was provided by MERCK.

\subsection{Particle size reduction for metal liberation}

To achieve efficient metal release, two steps of particle size reduction were realized. The first step consisted of shredding PCBs with a knife grinder, manufactured locally with initial particle sizes from $6 \mathrm{~cm}$ to 35 $\mathrm{cm}$. The second step consisted of cascade grinding by a hammer grinder Retsch SK 300 with grids of 5, 3, and $1.5 \mathrm{~mm}$. During this step, the temperature of the grinder chamber was about $113{ }^{\circ} \mathrm{C} \pm 1.5^{\circ} \mathrm{C}$. A particle size sorting was then carried out with a sieve shaker Retsch AS 300 control. Basing on literature data (Sarvar et al., 2015) to release the maximum metal particles from the polymer, the biggest sieve size was $1.5 \mathrm{~mm}$. Therefore, ten particle size portions were collected and analyzed ([1.5-1.4]; [1.4-1.0]; [1.0-0.71]; [0.71-0.355]; [0.355-0.250]; [0.250-0.180]; [0.180-0.125]; [0.125-0.090]; [0.090-0.063]; <0.063) mm. Scanning electron microscopy (SEM) combined with energy dispersive X-ray spectroscopy (EDX) experiments were carried out for microstructural characterization of sorted particles with a Hitachi SU8020 microscope at Materia Nova Research Center in Mons (Belgium).

\subsection{Elemental characterization of particle portions}

Fine grinding was carried out with a RETSCH grinder disc for two minutes to obtain particles size inferior to $125 \mu \mathrm{m}$. The particles were then dried at $50{ }^{\circ} \mathrm{C}$ for $24 \mathrm{~h}$ in an oven. Three digestion procedures were used to determine the most efficient for metal characterization in the PCBs. The first method consisted of leaching $1 \mathrm{~g}$ of the ground particles in a beaker with $20 \mathrm{~mL}$ of aqua regia solution (1:3 M proportion of $\mathrm{HNO}_{3}$ and $\mathrm{HCl}$ ), adapted of the analysis method ISO 11466:1995. The solution was stirred at $105^{\circ} \mathrm{C}$ in a watch-glass-covered beaker until a volume of approximately $5 \mathrm{~mL}$ was obtained after evaporation. The leachate was then filtered and diluted with a $\mathrm{HNO}_{3}$ solution. The second digestion method is adapted of the analysis method 3050B. It has consisted of mixing $10 \mathrm{~mL}$ of $\mathrm{HNO}_{3}$ with $1 \mathrm{~g}$ of ground particles; the mixture was stirred at $95{ }^{\circ} \mathrm{C}$ for $30 \mathrm{~min}$. Then $5 \mathrm{~mL}$ of $\mathrm{H}_{2} \mathrm{O}_{2}$ were added for the oxidation of the organic material. The solution was completed with 15 $\mathrm{mL}$ of $\mathrm{HCl}$, and after $30 \mathrm{~min}$ the remaining solution was recovered with a diluted $\mathrm{HNO}_{3}$ solution. The third procedure consisted of acid digestion by an Ethos Milestone microwave power $220 \mathrm{~V} / 50-60 \mathrm{~Hz}, 2.4 \mathrm{~kW}$. The HPR-ME-10 digestion program suitable for single metals and Ag, Au, Pd, and Pt alloys samples was applied. The whole digestion is carried out at a pressure of 45 bar. The program is starts by an increase of temperature to reach $220^{\circ} \mathrm{C}$ in $20 \mathrm{~min}$ followed by a dwelling time of $15 \mathrm{~min}$ before the decrease. $0.1 \mathrm{~g}$ of ground particles, $2 \mathrm{~mL}$ of $\mathrm{HNO}_{3}, 6 \mathrm{~mL}$ of $\mathrm{HCl}$, and 0.5 $\mathrm{mL}$ of $\mathrm{H}_{2} \mathrm{O}_{2}$ were mixed in a teflon vessel for this digestion program.

Metal concentrations were determined by ICP-AES with a Thermo Electron IRIS Intrepid II XSP instrument. 


\subsection{Determination of metal percentages in granulometric portions}

Particles were grinded for to get samples of size $<125 \mu \mathrm{m}$, and they were dried. After drying and grinding, particles were digested according to the procedure described for aqua regia and the metal content determined by ICP-AES. The metal proportion for each granulometric portion was calculated from Gámez et al. (2019) relation (1).

$P_{x}(\%)=\left(W^{*} 100\right) / W_{t}$

where:

$$
\begin{aligned}
& \mathrm{P}_{\mathrm{x}}=\text { Metal proportion (\%) content in the particle size portion } \\
& \mathrm{W}=\text { Metal mass in granulometric portion } \\
& \mathrm{W}_{\mathrm{t}}=\text { Total metal mass in all granulometric portions. }
\end{aligned}
$$

\section{Results and discussion}

\subsection{Influence of granulometric reduction on metal particles liberation}

It is well known that smaller the particles are better metal elements can be released from polymer supporting material of PCBs. The desired final particle size had to be inferior to $1.5 \mathrm{~mm}$ for efficient metal release (Sarvar et al., 2015). From initial dimensions ranging from approximately $35 \mathrm{~cm}$ to $6 \mathrm{~cm}$, the particles obtained after shredding were smaller than $20 \mathrm{~mm}$. Some were inferior to $1.4 \mathrm{~mm}$. The weight fraction of particles size inferior to $1.4 \mathrm{~mm}$ after shredding were respectively $33 \%, 25 \%, 16 \%$, and $51 \%$ for Mobile phone printed circuit boards, Computer printed circuit boards, Random Access Memory (RAM), and Processors. These particles were removed before performing the second size reduction. From grinding the obtained particle size were inferior to $1.5 \mathrm{~mm}$. The particles obtained after mechanical size reduction are composed of several types of material as specified by several authors (polymers, fiberglass, and metals) (Bachér et al., 2015; Hadi et al., 2015).

The particles obtained after grinding were subjected to a size sorting to produce the logarithmic curves representative of the cumulative weights in \% of the ground particles as presented in Fig. 1.

The curves showed a constant evolution of the slope between the class portions $-0.063 \mathrm{~mm}$ to [0.71-0.355] meaning that the quantities were fairly constant for these portions. But the proportions of the biggest particles were more important, as attested by the sudden sharpening of the curve. In general, all curves had the same shape, showing that the type of component had no significant influence on the results of grinding. The hammer mill was effective for secondary particle size reduction. The most important portions in weight were [0.71-0.355], [1.0-0.71] and [1.4-1.0] $\mathrm{mm}$ fractions. In each portion, different types of materials were observed: metals presented with a bright appearance and many morphologies, fiberglass presenting tapered morphology, and polymers with a green color.

EDX analyses were performed to estimate the mean elemental composition in some specific areas of the surface samples. The EDX results can be used to estimate the concentration of some chemical elements, but more importantly, used to assess the liberation level of the metals particles (Gonçalves and Otsuki, 2019; Otsuki et al., 2020). The data that were obtained for analysis of the different granulometric portions showed that the particles with dimensions inferior to $0.71 \mathrm{~mm}$ exhibited a better release of metals. Some metals were superimposed while other formed alloys, meaning that the size reduction techniques did not allow efficient separation leading to single metal release.

Polymer particles were attested by the presence of $\mathrm{C}$ and $\mathrm{O}$ in high content, as presented in Table 1 (particles portions 2, 3, and 6). The portions consisting mainly of metals were particle portions 1,4 , and 5 (Table 1). The major metals were encountered in large particle size portions while precious metals were predominant in small particle size portions.

The release of metals was improved when the particle size decreased. Some of the particles of the finest fraction were analyzed by MEB-EDX and the results were presented in Table 2. The metals particles analyzed (shiny particles) showed that they are constituted also of polymers and glass fibers and traces of silica. Some metal particles were constituted by a single metal while others were alloys. Particle 5 and 6 in Table 2 constituted by Fe, $\mathrm{Cr}$ and Ni could be identified as a stainlesssteel alloy. Particle portion 1 containing $\mathrm{Sn}$ and $\mathrm{Pb}$ originated probably from soldering alloy.

\subsection{Influence of digestion procedure on the elemental characterization of PCBs}

The concentration of twenty-one (21) metals occurring in PCBs is presented in Table 3. Precious metals (Au, Pd, Ag, etc.), magnetic metals ( $\mathrm{Co}, \mathrm{Fe}, \mathrm{Ni}$ ), potentially toxic metals $(\mathrm{Cr}, \mathrm{Pb}, \mathrm{As}, \mathrm{Hg}$, etc.), and some major metallic elements were identified in the granulometric portions.

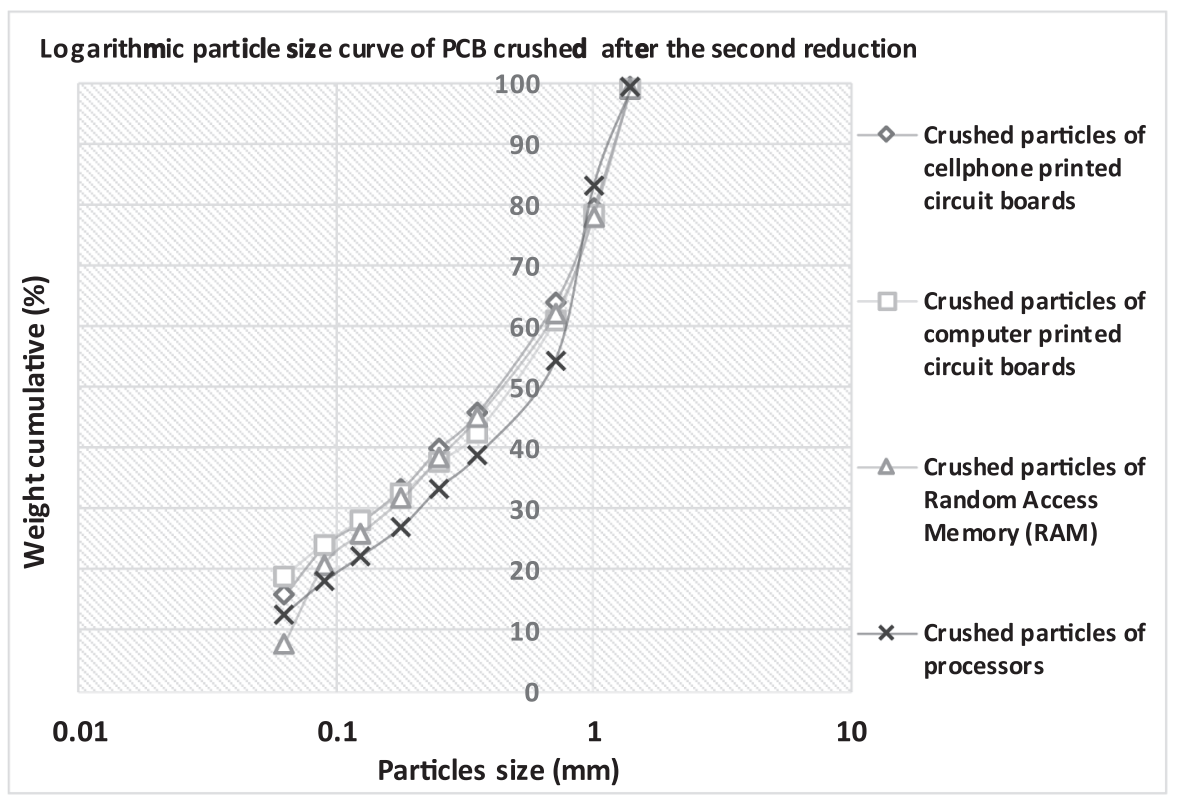

Fig. 1. Logarithmic particle size curve of PCBs crushed after the second reduction. 
Table 1

Composition of crushed PCBs particles for [0.71-0.355] mm granulometric fraction analyzed by SEM-EDX.

\begin{tabular}{|c|c|c|c|c|c|c|}
\hline \multirow[t]{2}{*}{ Chemical elements } & \multicolumn{6}{|c|}{ Wt. \% } \\
\hline & Particle 1 & Particle 2 & Particle 3 & Particle 4 & Particle 5 & Particle 6 \\
\hline C & $8.2 \pm 0.3$ & $33.3 \pm 0.5$ & $45.6 \pm 0.6$ & $15.9 \pm 0.7$ & $9.0 \pm 0.3$ & $48.3 \pm 0.6$ \\
\hline $\mathbf{O}$ & $19.7 \pm 1.4$ & $30.5 \pm 0.9$ & $35.9 \pm 0.9$ & $4.9 \pm 0.3$ & $13.0 \pm 0.3$ & $36.0 \pm 0.6$ \\
\hline Mg & - & $0.2 \pm 0.1$ & & & & $0.1 \pm 0.1$ \\
\hline Al & $1.5 \pm 0.2$ & $5.6 \pm 0.1$ & - & $0.8 \pm 0.2$ & $1.9 \pm 0.2$ & $5.9 \pm 0.5$ \\
\hline Si & $2.9 \pm 0.2$ & $5.8 \pm 0.1$ & $3.8 \pm 0.1$ & $0.8 \pm 0.1$ & - & $5.9 \pm 0.1$ \\
\hline $\mathbf{S}$ & $0.2 \pm 0.1$ & - & 0.2 & - & $0.3 \pm 0.1$ & - \\
\hline $\mathrm{Ca}$ & - & $1.6 \pm 0.1$ & $0.5 \pm 0.1$ & 0.1 & - & 0.2 \\
\hline $\mathrm{Fe}$ & - & $0.2 \pm 0.1$ & $0.3 \pm 0.1$ & - & $0.7 \pm 0.2$ & $0.5 \pm 0.1$ \\
\hline $\mathbf{N i}$ & $0.6 \pm 0.3$ & - & - & $1.8 \pm 0.4$ & - & - \\
\hline $\mathrm{Cu}$ & $4.9 \pm 0.9$ & $22.5 \pm 0.7$ & $5.3 \pm 0.5$ & $75.8 \pm 2.2$ & $2.3 \pm 0.4$ & $1.9 \pm 0.3$ \\
\hline $\mathrm{Br}$ & - & - & $8.1 \pm 0.2$ & - & - & $6.6 \pm 1.1$ \\
\hline Sn & $61.9 \pm 1.4$ & - & - & - & $70.1 \pm 14$ & - \\
\hline Ba & - & $0.3 \pm 0.1$ & $0.3 \pm 0.1$ & - & $2.8 \pm 0.3$ & - \\
\hline
\end{tabular}

Table 2

Composition of crushed PCBs particles of $-0.063 \mathrm{~mm}$ granulometric portion as analyzed by SEM-EDX.

\begin{tabular}{|c|c|c|c|c|c|c|}
\hline \multirow[t]{2}{*}{ Chemical elements } & \multicolumn{6}{|c|}{ Wt. \% } \\
\hline & Particle 1 & Particle 2 & Particle 3 & Particle 4 & Particle 5 & Particle 6 \\
\hline C & $8.8 \pm 0.3$ & $11.2 \pm 0.4$ & $8.6 \pm 0.4$ & $18.3 \pm 0.5$ & $4.3 \pm 0.2$ & $8.7 \pm 0.4$ \\
\hline $\mathbf{O}$ & $5.0 \pm 0.4$ & $3.7 \pm 0.5$ & $7.2 \pm 0.4$ & $8.4 \pm 0.5$ & $1.4 \pm 0.7$ & $6.0 \pm 0.7$ \\
\hline Al & $1.4 \pm 0.1$ & $1.8 \pm 0.2$ & $2.3 \pm 0.1$ & $1.4 \pm 0.2$ & $0.6 \pm 0.1$ & $1.0 \pm 0.1$ \\
\hline $\mathrm{Si}$ & - & $1.7 \pm 0.2$ & $0.7 \pm 0.1$ & $1.2 \pm 0.2$ & $1.4 \pm 0.1$ & $1.2 \pm 0.1$ \\
\hline $\mathrm{Ca}$ & 0.1 & $0.6 \pm 0.2$ & $0.2 \pm 0.1$ & $0.3 \pm 0.1$ & - & - \\
\hline $\mathrm{Cr}$ & - & - & - & - & $16.0 \pm 0.5$ & $14.7 \pm 0.3$ \\
\hline Mn & - & - & - & - & $1.4 \pm 0.3$ & $0.9 \pm 0.3$ \\
\hline $\mathrm{Fe}$ & - & - & - & $1.4 \pm 0.2$ & $67.7 \pm 1.1$ & $57.0 \pm 1.0$ \\
\hline $\mathrm{Ni}$ & - & - & - & - & $7.2 \pm 0.8$ & $6.5 \pm 0.8$ \\
\hline $\mathrm{Cu}$ & - & $81.0 \pm 1.6$ & $81.1 \pm 1.6$ & $69.0 \pm 1.5$ & - & $1.2 \pm 0.4$ \\
\hline Sn & $2.6 \pm 0.3$ & - & - & - & - & - \\
\hline $\mathbf{B a}$ & - & - & - & - & - & $1.9 \pm 0.5$ \\
\hline $\mathbf{P b}$ & $81.8 \pm 6.7$ & & & & & \\
\hline
\end{tabular}

Table 3

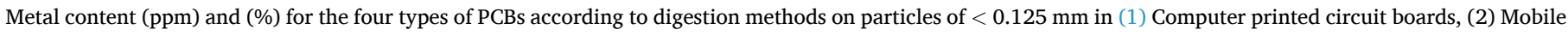
phone printed circuit boards; (3) Processors; (4) Random Access Memory (RAM).

\begin{tabular}{|c|c|c|c|c|c|c|c|c|c|c|c|c|c|}
\hline \multirow{2}{*}{$\frac{\text { Digestion Methods }}{\text { Composants }}$} & \multirow{2}{*}{-} & \multicolumn{4}{|c|}{$\mathrm{HCl}+\mathrm{HNO}_{3}+\mathrm{H}_{2} \mathrm{O}_{2}$} & \multicolumn{4}{|c|}{ Aqua regia } & \multicolumn{4}{|c|}{ Microwave digestion } \\
\hline & & (1) & $(2)$ & (3) & (4) & (1) & (2) & (3) & (4) & (1) & (2) & (3) & (4) \\
\hline \multirow[t]{7}{*}{ Precious metals (mg/kg) } & Ag & 750 & 861 & 128 & 537 & 543 & 478 & 109 & 520 & 718 & 1189 & 119 & 1507 \\
\hline & $\mathrm{Au}$ & 234 & 234 & 897 & 585 & 278 & 260 & 917 & 480 & 366 & 469 & 1381 & 940 \\
\hline & Pd & 251 & 2447 & 277 & 353 & 262 & 2345 & 246 & 942 & 245 & 2171 & 225 & 829 \\
\hline & Pt & 4.6 & 5.2 & 6.0 & 2.9 & 5.7 & 5.2 & 6.2 & 3.9 & 6 & 2.3 & 3.2 & 3.6 \\
\hline & Rh & - & - & - & - & 4.8 & 6.2 & 2.3 & 7.3 & - & - & - & 2.4 \\
\hline & $\mathbf{R u}$ & 10 & 185 & - & 11 & 357 & 3609 & 107 & 1286 & 386 & 3974 & 212 & 1259 \\
\hline & Ir & 4.3 & 15 & 54 & 20 & 2.9 & 11 & 48 & 3613 & - & 8 & 31 & 8 \\
\hline \multirow[t]{5}{*}{ Toxic metals (mg/kg) } & Cd & 9 & 15 & 12 & 6 & 9 & 15 & 11 & 9 & 11 & 15 & 8 & 9 \\
\hline & $\mathrm{Cr}$ & 733 & 11010 & 259 & 855 & 6161 & 6517 & 628 & 848 & 702 & 7345 & 411 & 2359 \\
\hline & $\mathrm{Hg}$ & - & - & - & - & - & - & 1,26 & - & - & - & - & - \\
\hline & As & 12 & 48 & 18 & 23 & 19 & 46 & 21 & 32 & 21 & 40 & 36 & 32 \\
\hline & $\mathrm{Pb}$ & 14254 & 7149 & 5895 & 7944 & 13530 & 7222 & 10684 & 9229 & 14912 & 8358 & 7802 & 8796 \\
\hline \multirow[t]{8}{*}{ Other metals (\%) } & Al & 2.0 & 0.7 & 0.2 & 0.5 & 2.6 & 1.6 & 2.3 & 1.9 & 3.1 & 2.1 & 1.6 & 1.8 \\
\hline & Co & 0.2 & 0.05 & 2.4 & 0.08 & 0.3 & 1.4 & 1.7 & 0.08 & 0.2 & 0.03 & 1.4 & 0.05 \\
\hline & $\mathrm{Cu}$ & 21.1 & 28.9 & 27.0 & 20.3 & 26.2 & 28.1 & 27.0 & 20.6 & 20.0 & 22.3 & 22.6 & 16.0 \\
\hline & $\mathbf{F e}$ & 3.7 & 8.8 & 9.8 & 3.9 & 6.4 & 9.0 & 7.4 & 4.3 & 4.5 & 6.6 & 4.9 & 4.6 \\
\hline & Mn & 0.06 & 0.2 & 0.05 & 0.07 & 0.1 & 0.2 & 0.06 & 0.1 & 0.06 & 0.1 & 35.9 & 0.08 \\
\hline & $\mathbf{N i}$ & 0.9 & 1.8 & 6.7 & 2.6 & 1.5 & 4.1 & 5.8 & 2.8 & 1.1 & 1.7 & 3.9 & 3.1 \\
\hline & Sn & 3.1 & 2.0 & 2.5 & 1.8 & 3.1 & 2.8 & 3.5 & 2.1 & 3.8 & 2.7 & 3.8 & 2.2 \\
\hline & $\mathrm{Zn}$ & 1.5 & 1.0 & 0.1 & 0.2 & 1.4 & 0.5 & 1.0 & 0.2 & 2.2 & 0.8 & 16.3 & 0.2 \\
\hline
\end{tabular}

Collected data revealed that $\mathrm{Cu}$ was the major metallic element for the four types of WEEEs, with an average content higher than $20 \mathrm{wt} \%$ as reported by previous studies (Hubau et al., 2019; Tunali et al., 2020). Al, $\mathrm{Co}, \mathrm{Fe}, \mathrm{Ni}, \mathrm{Sn}$, and $\mathrm{Zn}$ also occurred in relatively higher concentrations. Compared to natural mines contents in precious metals (Ag, $\mathrm{Au}, \mathrm{Pd})$ which are generally not higher than 20 ppm (Butler, 2011; Zuzolo et al.,
2018), the recovery of these metals from WEEEs exhibited very interesting yields (from 200 to over $2000 \mathrm{ppm}$ ) confirming the status of urban mines of that e-wastes (Ilankoon et al., 2019).

The proportions for the different metallic elements depended on the type of electronic waste. Despite changes in digestion procedures the differences in metal contents for the four types of electronic waste 
remained the same.

Thus, Pd was more abundant in Mobile phone printed circuit boards (2) than in other types of e-wastes. Pd release was not affected by the digestion procedure. Au was more abundant in Processors (3). Ag seemed more abundant in Mobile phone printed circuit boards (2), but the release of that metal was not very effective with aqua regia digestion. The observed variations in metal content depending on the digestion procedure could be due to sampling variability for each experience: indeed, even after effective mixing of the initial sample portion before sampling, the obtained samples for digestion remained heterogeneous (Sarvar et al., 2015).

Microwave digestion with the mixture acids $\mathrm{HCl}$ and $\mathrm{HNO}_{3}$ associated with $\mathrm{H}_{2} \mathrm{SO}_{4}$ has shown better results for the dissolution in general of the contents of precious metals compared to other methods of digestion method ISO 11466: 1995, and method 3050B adapted. Experiments generally highlighted that microwave digestion, leading to a complete dissolution in closed environment, presented the best results compared to the other digestion methods (association of $\mathrm{HNO}_{3}, \mathrm{HCl}, \mathrm{H}_{2} \mathrm{O}_{2}$, and aqua regia) (Jacques et al., 2014; Subhabrata and Yen-Peng, 2017). Au, $\mathrm{Ag}$, and Ru were better leached by the microwave digestion. However, Rh was leached by the aqua regia digestion method for all types of WEEEs, and only for Random-access memory (RAM) after microwave digestion.

Nevertheless, mercury ( $\mathrm{Hg}$ ) was not released by microwave digestion but with aqua regia digestion in the case of Processors (3). Interferences must have intervened in the digestion of the other metals due to the heterogeneity of the particles. Literature available data confirm the influence of sampling on the variability of metal content from WEEEs (Laubertova et al., 2019; Mählitz et al., 2020).

It is noticeable that the metal content in PCBs from the present study was significantly different from those of previous studies except the one of Oguchi et al. (2013). For precious metals, the concentrations of Au and Ag were in the same range for Oguchi et al. (2013). However, Pd concentrations were significantly higher in mobile phones than in all previous studies. $\mathrm{Cu}$ was the main element from all studies with about more than $20 \mathrm{wt} \%$ of the total metal content, excepted in data presented by Ogunniyi et al. (2009) who reported much lower Cu content for PCBs. The assessment of $\mathrm{Hg}$ appeared challenging for all studies. $\mathrm{Pb}$ was abundant in all studies. Cd, another toxic metal was in much lower concentrations. The present study reported higher content of toxic $\mathrm{Cr}$ than previous papers. For all studies, the main metals were $\mathrm{Al}, \mathrm{Cu}, \mathrm{Fe}, \mathrm{Ni}$, Sn, and Pb (Gámez et al., 2019; Hall and Williams, 2007; Stellan et al., 2016). However, it must be noted that, the disc grinding having been carried out on a sampled fraction of the particles $<1.5 \mathrm{~mm}$ obtained after the secondary grinding (hammer grinding); the metal contents obtained is related to this fraction. Sampling of a different amount could have an influence on the representativeness of initial metal content, because to the heterogeneity of the particles of the starting fraction.

In their study, (Mičková et al., 2018) have found that microwave digestion with $\mathrm{HCl}-\mathrm{HNO}_{3}-\mathrm{H}_{2} \mathrm{O}_{2}$ was more efficient than the digestions realised with aqua regia, and $\mathrm{HCl}-\mathrm{HNO}_{3}-\mathrm{H}_{2} \mathrm{O}_{2}$ mixtures. (Tunali et al., 2020) have obtained the same conclusions, mainly for the precious metal recovery, in their study that addresses the same comparison of the three analysed methods. Our conclusions are in adequation with those of the literature: a total microwave digestion method using the mixture of the acid solutions $\mathrm{HCl}-\mathrm{HNO}_{3}$ with $\mathrm{H}_{2} \mathrm{O}_{2}$ appears to be the best digestion method for the treatment of precious metals.

In addition, several other studies on digestion methods have figured out that the heterogeneity of the samples has an impact on the results interpretation (Remeteiová et al., 2020; Subhabrata and Yen-Peng, 2017).

\subsection{Metals characterization for the different granulometric portions}

After shredding and grinding different types of WEEEs it was important to characterize the metal content for each portion. This helps determine the best granulometric portion for the optimal concentration of metals of interest. Experiments were carried out for the four classes of WEEEs (computer PCBs, Mobile phone PCBs, Processors, and RAMs). Metal contents were determined by ICP-AES after aqua regia digestion.

\subsubsection{Distribution of metals in the granulometric fractions of crushed computers PCBs}

Precious metals content in computer PCBs as reported in Fig. 2 showed that $\mathrm{Au}$ and $\mathrm{Ag}$ were homogeneously spread in all portions with a predominance in $<0.063$ and [1.4-1.0] mm portions. However, Pd was very concentrated in the [1.4-1.0] mm class with up to $70 \%$ for this metal. Oliveira et al. (2010) showed that gold (Au) distribution in granulometric fractions of ground PCBs did not depend on the size portions while silver $(\mathrm{Ag})$ concentration increased when the size of particle portions decreased.

Major metals were also distributed in all classes as presented in Fig. 2. These elements were predominant in the [1.0-0.71] and [1.4-1.0] mm fractions and lower in [0.71-0.355] mm portion. Only Al and Fe were significantly concentrated in the smallest portion $(<0.063$ $\mathrm{mm})$.

\subsubsection{Distribution of metals in the granulometric fractions of crushed mobile phones $P C B s$}

The distribution of metal content for different granulometric portions is presented in Fig. 3. From this figure, it appeared that $\mathrm{Ag}$ and $\mathrm{Au}$ were distributed in all class portions with a preference for $<0.063$ and [1.4-1.0] mm fractions. As for computer PCBs, Pd was very concentrated in [1.4-1.0] and [1.0-0.71] mm portions with respectively $66 \%$ and $14 \%$ of total Pd in those fractions. Fig. 3 exhibited that the major metals were distributed in all the class portions. However, $\mathrm{Cr}, \mathrm{Fe}$, and Mn were specifically concentrated in [1.4-1.0] class portion, representing respectively 65,68 , and $65 \%$ of the total metal content. $\mathrm{Al}, \mathrm{Cu}$, $\mathrm{Pb}$, and $\mathrm{Sn}$ were more or less present in all class portions.

Ani et al. (2020) showed that both major and precious metals are more important in the fractions with the largest particle sizes. Palladium (Pd) was exclusively concentrated in intermediate particle size ([1-0.5] $\mathrm{mm}$ ). The larger particle size for these authors was $4 \mathrm{~mm}$ while it was $1.5 \mathrm{~mm}$ for the present study. It can be assumed that for the [4-1] mm particle portion Pd is not released from the supporting material. And under $0.5 \mathrm{~mm}$ particle size, there is no more Pd in the portion.

\subsubsection{Distribution of metals in the granulometric fractions of crushed processors}

The distribution of precious metals according to granulometric portions (Fig. 4) showed that silver (Ag) was well distributed in all portions with a preference for the smaller ones. On the contrary gold (Au) and palladium (Pd) were respectively highly concentrated in [1.4-1.0] and [1.0-0.71] mm fractions; these portions represented respectively $52 \%$ and $62 \%$ of the total content for Au and Pd.

From Fig. 4 it appeared that the major magnetic metals (Co, Fe, and $\mathrm{Ni}$ ) were highly concentrated in the [1.4-1.0] and [1.0-0.71] portions (respectively $95 \%, 85 \%$, and $90 \%$ of the total metal amount). However, for other major metals $(\mathrm{Cr}, \mathrm{Cu}, \mathrm{Pb}, \mathrm{Sn}$, and $\mathrm{Zn}$ ), significant amounts were present in all portions. About $50 \%$ of aluminum (Al) were in the finer fraction.

\subsubsection{Distribution of metals in the granulometric fractions of crushed random-access memory (RAM)}

Data reported in Fig. 5 showed that silver $(\mathrm{Ag})$ and palladium (Pd) were present in significant quantities in the [1.4-1.0] and [1.0-0.71] $\mathrm{mm}$ fractions, representing more than $70 \%$ of the total precious metal content. Pd preferentially occurred in [1.4-1.0] and [1.0-0.71] fractions but was well distributed in the other particle size portions. Magnetic metals (Co, Fe, and $\mathrm{Ni}$ ) and $\mathrm{Zn}$, as shown in Fig. 5 were abundant in [1.4-1.0] and [1.0-0.71] mm portions with more than $75 \%$ of the total amount of major metal content. The other major metals (Al, $\mathrm{Cr}, \mathrm{Cu}, \mathrm{Mn}$, 


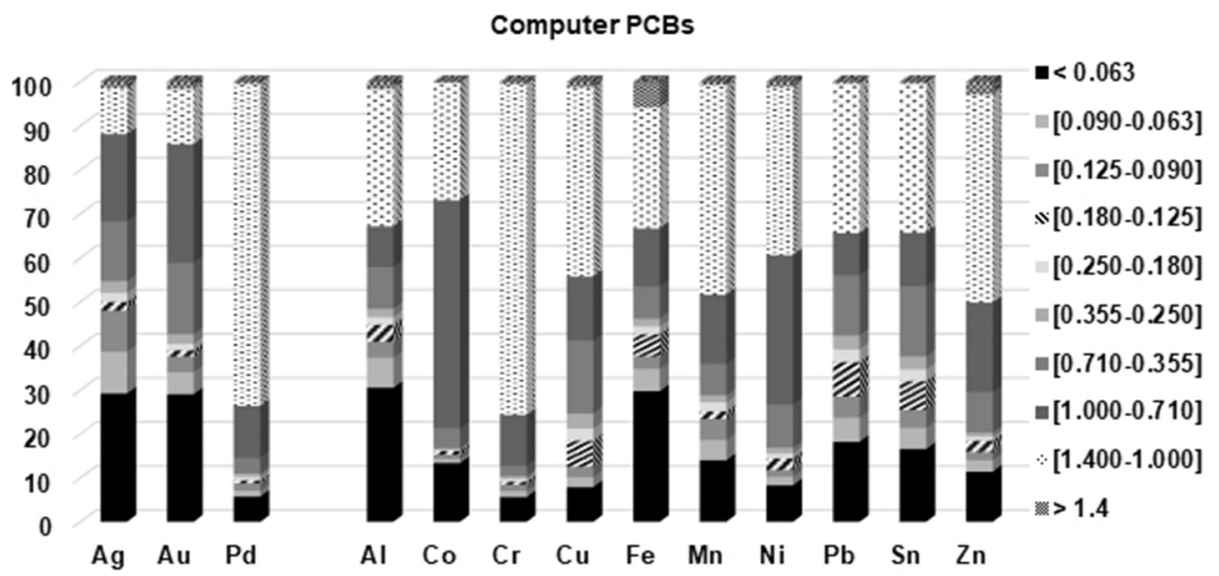

Fig. 2. Precious metals and Major metals distribution in the particle size portion for computer PCB (\% w/w).

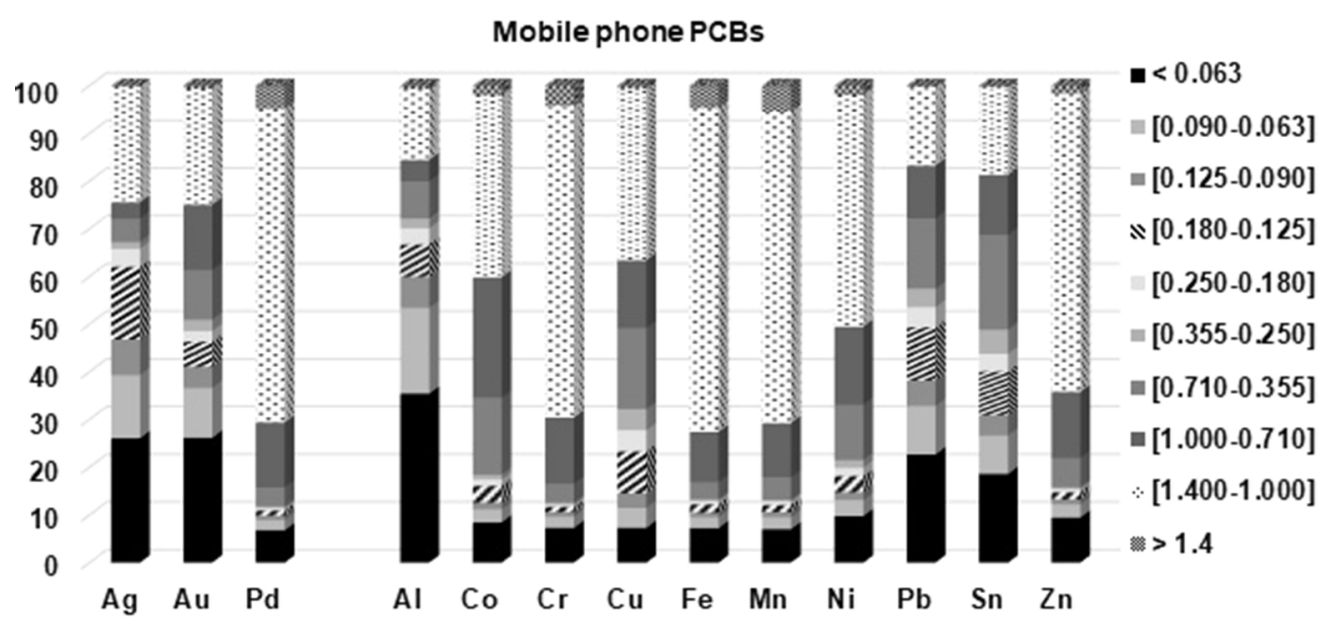

Fig. 3. Precious metals and Major metals distribution in particle size portions for mobile phone PCB (\% w/w).

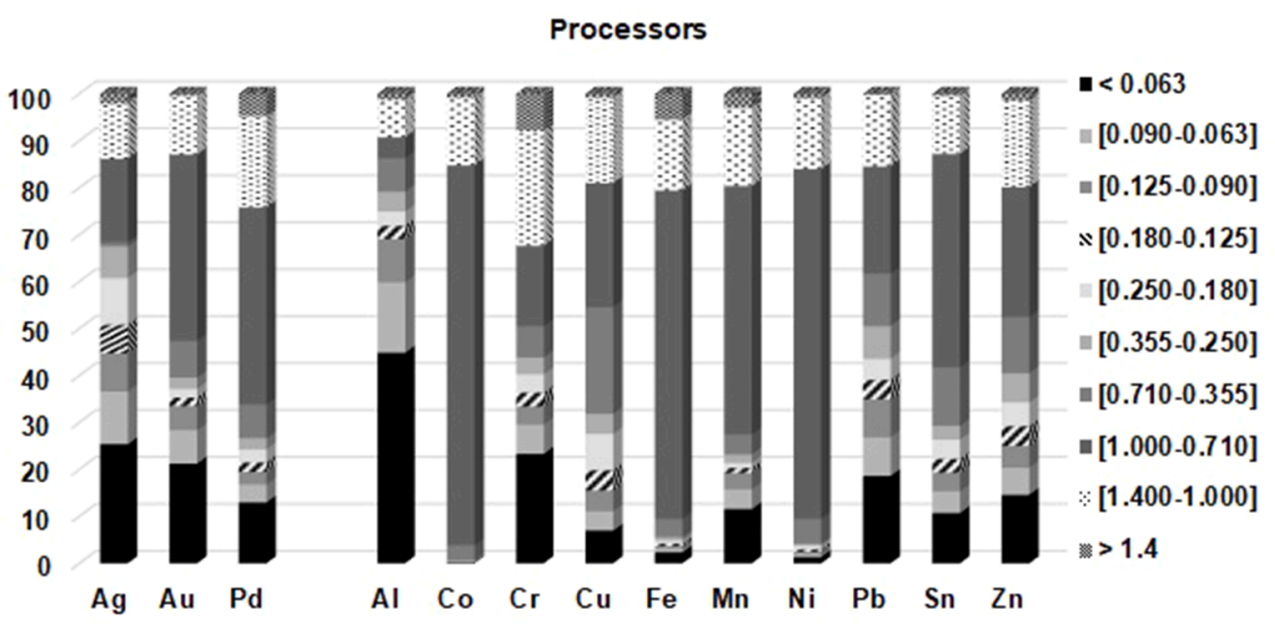

Fig. 4. Precious metals and Major metals distribution in particle size portions for processors (\% w/w).

$\mathrm{Pb}, \mathrm{Sn})$ were distributed in all portions with a preference for the [1.4-1.0] and [1.0-0.71] mm fractions.

\section{Conclusion}

The granulometric size reduction process by shredding and grinding showed an effective release of the particles from the studied PCBs, for a granulometric smaller than $0.71 \mathrm{~mm}$. The SEM analysis showed that free metal particles, whatever their size, were most of the time associated with other metals or non-metallic materials. Therefore, it was hard to achieve a total release of specific metal by grinding. Chemical analysis showed that the metal content depended on both PCBs type and 


\section{Random Access Memory}

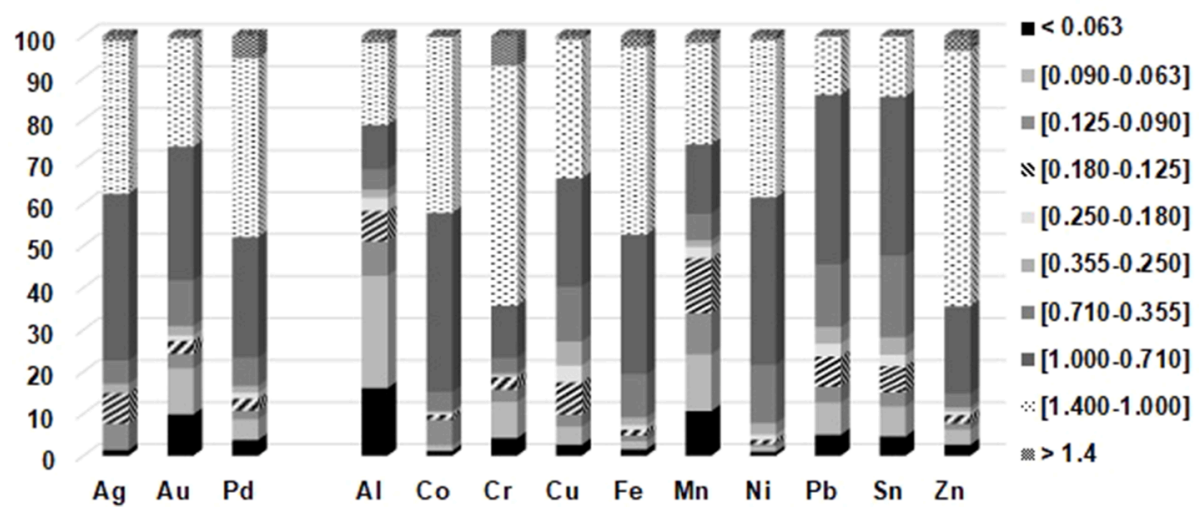

Fig. 5. Precious metals and Major metals distribution in particle size portions for RAM (\% w/w).

digestion procedure. Microwave-assisted digestion led to better metal leaching than other open environment hotplate digestion methods. The concentrations of precious metals were quite high and confirmed the interest in developing procedures for environmental-friendly metal recovery in WEEE collected in Burkina Faso. It appeared from metal distribution in granulometric portions data that metals were distributed most of the time in all size classes. Therefore, granulometric separation could not be seriously implemented for efficient recovery of metals from WEEE. It would be more suitable to envisage a strategy for the concentration of metals, specifically precious metals (Ag, Au, Pd) to recover metals whatever the granulometric size fraction.

\section{Declaration of Competing Interest}

The authors declare that they have no known competing financial interests or personal relationships that could have appeared to influence the work reported in this paper.

\section{Acknowledgments}

This work was financially supported by ARES-CCD and the authors would like to thank Materia Nova Research Center in Mons (Belgium) for SEM-EDS analysis.

\section{References}

Achillas, C., Aidonis, D., Vlachokostas, C., Karagiannidis, A., Moussiopoulos, N., Loulos, V., 2013. Depth of manual dismantling analysis: A cost-benefit approach. Waste Manag. 33, 948-956. https://doi.org/10.1016/j.wasman.2012.12.024.

Alzate, A., López, M.E., Serna, C., 2016. Recovery of gold from waste electrical and electronic equipment (WEEE) using ammonium persulfate. Waste Manag. 57, 113-120. https://doi.org/10.1016/j.wasman.2016.01.043.

Ani, A., Bedekovi, G., Šarc, R., Premur, V., 2020. Determining Metal Content in Waste Printed Circuit Boards and their Electronic Components. J. Sustain. Dev. Energy. Water Environ. Syst. 8, 590-602. https://doi.org/10.1016/j.wasman.2016.01.043.

Arora, R., Paterok, K., Banerjee, A., Singh, M., 2017. Potential and relevance of urban mining in the context of sustainable cities. IIMB Manag. Rev. 29, 210-224. https:// doi.org/10.1016/j.iimb.2017.06.001.

Bachér, J., Mrotzek, A., Wahlström, M., 2015. Mechanical pre-treatment of mobile phones and its effect on the Printed Circuit Assemblies (PCAs). Waste Manag. 45, 235-245. https://doi.org/10.1016/j.wasman.2015.06.009.

Bimir, M.N., 2020. Revisiting e-waste management practices in selected African countries Revisiting e-waste management practices in selected African countries. J. Air Waste Manage. Assoc. 70, 659-669. https://doi.org/10.1080/ 10962247.2020.1769769.

Buekens, A., Yang, J., 2014. Recycling of WEEE plastics: A review. J. Mater. Cycles Waste Manag. 16, 415-434. https://doi.org/10.1007/s10163-014-0241-2.

Butler, D.A.H.I.M.I.B., 2011. Precious metal enrichment in the Platreef, Bushveld Complex , South Africa : evidence from homogenized magmatic sulfide melt inclusions 1011-1026. 10.1007/s00410-010-0577-0.

Cesaro, A., Belgiorno, V., Vaccari, M., Jandric, A., Chung, T.D., Dias, M.I., Hursthouse, A., Salhofer, S., 2018. A device-specific prioritization strategy based on the potential for harm to human health in informal WEEE recycling. Environ. Sci. Pollut. Res. 25, 683-692. https://doi.org/10.1007/s11356-017-0390-7.
Gámez, S., Garcés, K., Torre, E.D., Guevara, A., 2019. Hydrometallurgy Precious metals recovery from waste printed circuit boards using thiosulfate leaching and ion exchange resin. Hydrometallurgy 186, 1-11. https://doi.org/10.1016/j. hydromet.2019.03.004.

Ghosh, B., Ghosh, M.K., Parhi, P., Mukherjee, P.S., Mishra, B.K., 2015. Waste Printed Circuit Boards recycling: An extensive assessment of current status. J. Clean. Prod. 94, 5-19. https://doi.org/10.1016/j.jclepro.2015.02.024.

Gonçalves, P.P., Otsuki, A., 2019. Determination of Liberation Degree of Mechanically Processed Waste Printed Circuit Boards by Using the Digital Microscope and SEMEDS Analysis. electronics. 10.3390/electronics8101202.

Guo, C., Wang, H., Liang, W., Fu, J., Yi, X., 2011. Liberation characteristic and physical separation of printed circuit board (PCB). Waste Manag. 31, 2161-2166. https://doi. $\operatorname{org} / 10.1016 /$ j.wasman.2011.05.011.

Hadi, P., Xu, M., Lin, C.S.K., Hui, C., Mckay, G., 2015. Waste printed circuit board recycling techniques and product utilization. J. Hazard. Mater. 283, 234-243. https://doi.org/10.1016/j.jhazmat.2014.09.032.

Hall, W.J., Williams, P.T., 2007. Separation and recovery of materials from scrap printed circuit boards. Resour. Conserv. Recycl. 51, 691-709. https://doi.org/10.1016/j. resconrec.2006.11.010.

Hubau, A., Chagnes, A., Minier, M., Touzé, S., Chapron, S., Guezennec, A.G., 2019. Recycling-oriented methodology to sample and characterize the metal composition of waste Printed Circuit Boards. Waste Manag. 91, 62-71. https://doi.org/10.1016/ j.wasman.2019.04.041.

Ilankoon, I.M.S.K., Ghorbani, Y., Nan, M., Herath, G., Moyo, T., 2019. E-waste in the international context - A review of trade flows, regulations, hazards, waste management strategies and technologies for value recovery. Metals (Basel). 82 , 258-275. https://doi.org/10.1016/j.wasman.2018.10.018.

Jacques, Y., Bezerra, A., Biondi, C.M., 2014. Comparison of USEPA digestion methods to heavy metals in soil samples. Env. Monit Assess 47-53. https://doi.org/10.1007/ s10661-013-3354-5.

Jadhav, U., Hocheng, H., 2015. Hydrometallurgical Recovery of Metals from Large Printed Circuit Board Pieces. Nat. Publ. Gr. 1-10 https://doi.org/10.1038/ srep14574.

Kaya, M., 2016. Recovery of metals and nonmetals from electronic waste by physical and chemical recycling processes. Waste Manag. 57, 64-90. https://doi.org/10.1016/j. wasman.2016.08.004.

Khaliq, A., Rhamdhani, M., Brooks, G., Masood, S., 2014. Metal Extraction Processes for Electronic Waste and Existing Industrial Routes: A Review and Australian Perspective. Resources 3, 152-179. https://doi.org/10.3390/resources3010152.

Kitane, M., Benqlilou, C., El Kacimi, K., Lotfi, E.M., 2015. Valorisation des DEEE par l'extraction des terres rares, métaux précieux et matières plastiques. Déchets, Sci. Tech. 41-47. 10.4267/dechets-sciences-techniques.3242.

Laubertova, M., Malindzakova, M., Trpcevska, J., Gajić, N., 2019. Assessement of sampling and chemical analysis of waste printed circuit boards from WEEE : Gold content determination. Metall. Mater. Eng. 10 (30544/427).

Lee, J., Kim, K., Cho, H., Ok, J., Kim, S., 2017. Shredding and liberation characteristics of refrigerators and small appliances. Waste Manag. 59, 409-421. https://doi.org/ 10.1016/j.wasman.2016.10.030.

Li, H., Eksteen, J., Oraby, E., 2018. Hydrometallurgical recovery of metals from waste printed circuit boards (WPCBs): Current status and perspectives - A review. Resour. Conserv. Recycl. 139, 122-139. https://doi.org/10.1016/j.resconrec.2018.08.007.

Li, J., Lopez N., B.N., Liu, L., Zhao, N., Yu, K., Zheng, L., 2013. Regional or global WEEE recycling. Where to go? Waste Manag. 33, 923-934. 10.1016/j. wasman.2012.11.011.

Mählitz, P.M., Korf, N., Sperlich, K., Münch, O., Rösslein, M., Rotter, V.S., 2020. Characterizing the Urban Mine - Simulation-Based Optimization of Sampling Approaches for Built-in Batteries in WEEE. recycling. 5, 2313-4321. 10.3390/ recycling5030019.

Maphosa, V., Maphosa, M., Tan, A.W.K., 2020. E-waste management in Sub-Saharan Africa : A E-waste management in Sub-Saharan Africa : A systematic literature review. Cogent Bus. Manag. 10.1080/23311975.2020.1814503. 
Mičková, V., Ružičková, S., Remeteiová, D., Laubertová, M., Dorková, M., 2018. Sampling and digestion of waste mobile phones printed circuit boards for $\mathrm{Cu}, \mathrm{Pb}, \mathrm{Ni}$, and Zn determination. Chem. Pap. 72, 1231-1238. https://doi.org/10.1007/s11696017-0353-y.

Oguchi, M., Sakanakura, H., Terazono, A., 2013. Science of the Total Environment Toxic metals in WEEE : Characterization and substance fl ow analysis in waste treatment processes. Sci. Total Environ. 463-464, 1124-1132. https://doi.org/10.1016/j. scitotenv.2012.07.078.

Ogunniyi, I.O., Vermaak, M.K.G., Groot, D.R., 2009. Chemical composition and liberation characterization of printed circuit board comminution fines for beneficiation investigations. Waste Manag. 29, 2140-2146. https://doi.org/ 10.1016/j.wasman.2009.03.004.

Oliveira, P.C., Cabral, M., Nogueira, C.A., Margarido, F., 2010. Printed Circuit Boards Recycling : Characterization of Granulometric Fractions from Shredding Process. Mater. Sci. Forum 637, 1434-1439. https://doi.org/10.4028/www.scientific.net/ MSF.636-637.1434.

Ongondo, F.O., Williams, I.D., Cherrett, T.J., 2011. How are WEEE doing ? A global review of the management of electrical and electronic wastes. Waste Manag. 31, 714-730. https://doi.org/10.1016/j.wasman.2010.10.023.

Otsuki, A., La, L.D., King, A., Serranti, S., Fiore, L., Bonifazi, G., 2020. Non-destructive characterization of mechanically processed waste printed circuit boards - particle liberation analysis. Waste Manag. 102, 510-519. https://doi.org/10.1016/j. wasman.2019.11.006.

Petter, P.M.H., Veit, H.M., Bernardes, A.M., 2014. Evaluation of gold and silver leaching from printed circuit board of cellphones. Waste Manag. 34, 475-482. https://doi. org/10.1016/j.wasman.2013.10.032.

Rachid, I.R.M., 2018. Etude sur la gestion des déchets d'équipement électriques et électroniques (D3E) à Ouagadougou, BURKINA FASO. 2IE, Glob. water Sustain. http://documentation.2ie-edu.org/cdi2ie/opac_css/doc_num.php?explnum_ $\mathrm{id}=2594$.

Rajarao, R., Sahajwalla, V., Cayumil, R., Park, M., Khanna, R., 2014. Novel Approach for Processing Hazardous Electronic Waste. Procedia Environ. Sci. 21, 33-41. https:// doi.org/10.1016/j.proenv.2014.09.005.

Remeteiová, D., Ružičková, S., Mičková, V., Laubertová, M., Slezáková, R., 2020. Evaluation of US EPA Method 3052 Microwave Acid Digestion for Quantification of Majority Metals in Waste Printed Circuit Boards. Metals 10 (11), 1511. https://doi. org/10.3390/met10111511.
Sarvar, M., Salarirad, M.M., Shabani, M.A., 2015. Characterization and mechanical separation of metals from computer Printed Circuit Boards (PCBs) based on mineral processing methods. Waste Manag. 45, 246-257. https://doi.org/10.1016/j. wasman.2015.06.020.

Shittu, O.S., Williams, I.D., Shaw, P.J., 2021. Global E-waste management: Can WEEE make a difference? A review of e-waste trends, legislation, contemporary issues and future challenges. Waste Manag. 120, 549-563. https://doi.org/10.1016/j. wasman.2020.10.016.

Souza, J.P., Freitas, P.E., Almeida, L.D., Rosmaninho, M.G., 2017. Development of new materials from waste electrical and electronic equipment: Characterization and catalytic application. Waste Manag. 65, 104-112. https://doi.org/10.1016/j. wasman.2017.03.051.

Stellan, H., Britt-Marie, S., Max, B., Klas, C., 2016. Analysis of the metal content of smallsize Waste Electric and Electronic Equipment (WEEE) printed circuit boards-part 1: Internet routers, mobile phones and smartphones. Resour. Conserv. Recycl. 1-9 https://doi.org/10.1016/j.resconrec.2017.02.011.

Subhabrata, D., Yen-Peng, T., 2017. Evaluation of Wet Digestion Methods for Quantification of Metal Content in Electronic. Resources. https://doi.org/10.3390/ resources6040064.

Tian, X., Wu, Y., Qu, S., Liang, S., Xu, M., Zuo, T., 2018. Modeling domestic geographical transfers of toxic substances in WEEE: A case study of spent lead-acid batteries in China. J. Clean. Prod. 198, 1559-1566. https://doi.org/10.1016/j. jclepro.2018.07.089.

Tunali, M., Tunali, M.M., Yenigun, O., 2020. Characterization of diferent types of electronic waste - heavy metal, precious metal and rare earth element content by comparing diferent digestıon methods.pdf. J. Mater. Cycles Waste Manag. 23, 149-157. https://doi.org/10.1007/s10163-020-01108-0.

Wang, H., Zhang, G., Hao, J., He, Y., Zhang, T., 2018. Morphology, mineralogy and separation characteristics of nonmetallic fractions from waste printed circuit boards. J. Clean. Prod. 170, 1501-1507. https://doi.org/10.1016/j.jclepro.2017.09.280.

Zuzolo, D., Cicchella, D., Doherty, A.L., Albanese, S., Lima, A., De Vivo, B., 2018. The distribution of precious metals (Au, Ag, Pt, and Pd) in the soils of the Campania Region (Italy). J. Geochemical Explor. 192, 33-44. https://doi.org/10.1016/j. gexplo.2018.03.009.

Zhang, S., Ding, Y., Liu, B., Chang, C. chi, 2017. Supply and demand of some critical metals and present status of their recycling in WEEE. Waste Manag. 65, 113-127. 10.1016/j.wasman.2017.04.003. 